\title{
VALIDATION OF ANALYTICAL METHOD BY UV SPECTROPHOTOMETRIC QUANTIFICATION OF GEMFIBROZIL INCORPORATED IN THE MICROEMULSIONS
}

\author{
María Herrera P. ${ }^{1}$, José Cantos C. ${ }^{1}$, Kevin Muñoz S. ${ }^{1}$, Jovan Durán A. ${ }^{2}$, \\ Julio Vinueza G. ${ }^{3}$ \& Fernanda Kolenyak-S..$^{*}$
}

Recibido: 23 de octubre 2020 / Aceptado: 14 de diciembre 2020 DOI: 10.26807/ia.v9i1.195

\begin{abstract}
Keywords: Analytical Validation, Gemfibrozil, Microemulsions, UV spectrophotometric
\end{abstract}

\begin{abstract}
The present study aims to validate an analytical method by UV spectrophotometric for the quantification of gemfibrozil incorporated into microemulsions. Experimental development by constructing a ternary phase diagram for the identification of microemulsions. The characterization of the microemulsions was

1 Universidad de Guayaquil, Facultad de Ciencias Químicas, Guayaquil, Ecuador. (mariaelizabethherreraparedes@gmail.com; josecantossc@gmail.com; kevinjoelmuoz25@hotmail.es; *correspondência: fernandakolenyak@outlook.com)

2 Universidade Estadual Paulista (UNESP), Instituto de Química, Departamento de Química Analítica, Araraquara, SP, Brasil (alonso.jdr@gmail.com;)

3 Pontificia Universidad Católica del Ecuador, Facultad de Ciencias Exactas y Naturales, Escuela de Química, Quito, Ecuador (julio_vinueza@hotmail.com)
\end{abstract}


carried out by the polarized light microscopy technique. The analytical method was validated according to the parameters described by the United State Pharmacopeia (USP) 39 NF34 and International Conference on Harmonization (ICH) (2005), which evaluated linearity, robustness, intra and inter day accuracy, specificity accuracy, limits of detection and quantification. The developed method demons trated linearity with a coefficient of determination (R2) of 0.9898, in addition to precision, accuracy and robustness for each of the tests with values that presented a coefficient of variation of less than $5 \%$. The results obtained were favorable, since they comply with the parameters stipulated by USP 39-NF34 (2016) and ICH (2005), indicating that the method is effective for the intended purpose.

\section{INTRODUCTION}

The prolonged drug release systems are classified as new technological alternatives used to control the concentration and time of drug release after administration. These systems can be solid dispersions, micro and nanoparticles, liposomes, microemulsions etc. (Huo et al., 2017; Davoodi et al., 2018; El Maghraby, Arafa, \& Essa, 2018).

Microemulsions (MEs), are systems composed of water and oil that are stabilized by surfactants, their main characteristic is thermodynamic stability, due a large amount of energy is not required for their formation.
Unlike emulsions, microemulsions have transparent aspects, this is It is due to the small size of the particles, which can reach $500 \mathrm{~nm}$. ME can be characterized as oil in water $(\mathrm{O} / \mathrm{W})$ and water in oil (W/O), which confers the particularity of being able to incorporate lipophilic and hydrophilic drugs (Callender et al., 2017; Ferreira et al., 2018; Gvaramia et al., 2018).

Gemfibrozil (GFZ) is a drug that acts as a cholesterol reducer, derived from fabric acid and chemically known as 5- (2,5-dimethylphenoxy) -2,2-dimethylpentanoic acid. Its prescription is 
also made in order to reduce the risk of stroke, heart attack or other cardiac complications as it increases high density lipoproteins (LDL) (Tornio et al., 2017). Despite having studied the interactions, it is not yet possible to accurately quantify the drug within the systems matrix due to the lack of validated methods for this purpose.

The validation of a methodology is important as it aims to demonstrate the suitability of the method to carry out an analysis. The methods of analysis used in the quality control of pharmaceutical products must have been validated prior to routine use. The validation of a test method is intended to demonstrate the suitability of the method to carry out an analysis (USP 39 NF 34 2016; ICH, 2005; Cáñez \& García, 2015).

Ultraviolet-Visible Spectroscopy (UVVis) is a technique that is based on the ability of certain molecules to absorb radiation such as those corresponding to the visible UV spectrum. The use of a spectrophotometer allows readings in a wavelength range of 190 to $800 \mathrm{~nm}$, simultaneously considering factors such as atomic structure, medium conditions $(\mathrm{pH}$, temperature, ionic strength, dielectric constant) which finally makes the information provided of the energy states, atomic or molecular, of the study sample allow its determination and characterization. The UVspectrophotometry is an inexpensive, easy, reliable, fast and useful, meets the requirements of quality control of pharmaceutical and cosmetic industries. As an alternative to the existing method by HPLC (Valcárcel, Gonzáles y Valcárcel, 2008; Cubas et al., 2018; Maldonado et al., 2018). The aim of this work is to validate an analytical method to gemfibrozil incorporated in the microemulsions.

\section{MATERIALS AND METHODS}

\section{Materials}

Sodium Chloride $(\mathrm{NaCl})$, Potassium Chloride $(\mathrm{KCl})$, Calcium Chloride
$\left(\mathrm{CaCl}_{2}\right)$, Sodium Phosphate $\left(\mathrm{NaHPO}_{4}\right)$, Glucose $\left(\mathrm{C}_{6} \mathrm{H}_{12} \mathrm{O}_{6}\right)$, Sodium Hydroxide $(\mathrm{NaOH})$, Gemfibrozil were purchased from Sigma-Aldrich CO (USA). 


\section{Methods}

\section{Phase diagram construction}

The ternary phase diagram was prepared using tween80, oleic acid and Milli Q water at $25{ }^{\circ} \mathrm{C}$. In the mixture of water/oil was added the surfactant until the solution is completely transparent, which was indicative of the formation of the single phase. Once the candidate sample was separated, the sample was prepared with and without drug for the validation of the analytical methodology.

\section{Polarized light microscopy}

The microemulsion structure was analyzed by means of a photomicroscope (Leica DMLP microscope) equipped with a camera: firstly, under the bright field and secondly, under the polarized light (using crosspolarizers) in order 5 to investigate the presence of the liquid crystalline phase in each sample. Leica IM 1000 software was used to analyze the obtained micrographs.

\section{Preparation of buffer TC199 with glucose at $\mathrm{pH} 7.4$}

The buffer was prepared according described by Silva et al (2008). Briefly
$145 \mathrm{mM} \mathrm{NaCl} ; 4.56 \mathrm{mM} \mathrm{KCl} ; 1.25$ $\mathrm{mM} \mathrm{CaCl} 22_{2} \mathrm{H}_{2} \mathrm{O} ; 5 \mathrm{mM} \mathrm{NaHPO}$ were weighed and leading to a final volume of $1000 \mathrm{~mL}$ of Milli Q water, the glucose was added, and the solution was adjusted to a $\mathrm{pH}$ of 7.4 using $1 \mathrm{~N} \mathrm{NaOH}$.

\section{Analytical method validation}

The methodology was performed using the parameters defined by USP 39 NF 34 (2016) and ICH Q2 (2005). All analyzes were performed at a wavelength of $276 \mathrm{~nm}$, this value refers to the maximum absorption wavelength of GFZ (USP 38, 2015).

\section{Linearity}

The linearity of the method was determined by obtaining three analytical curve of gemfibrozil/microemul sion (GFZ/MEs) in absolute ethanol (250 mg/mL). Transferred aliquots of stock solution to a volumetric flask to obtain nine concentrations, from 0.02 to $0.09 \mathrm{mg} / \mathrm{mL}$ of GFZ and the volume was completed with absolute ethanol, then the absorbance-absorbance of the samples were measured in $276 \mathrm{~nm}$ using blank ethanol. The dilutions were prepared in triplicate. 


\section{Precision}

The data were analyzed at a wavelength $276 \mathrm{~nm}$. The precision of the analytical curves was determined in three consecutive days for intra- and inter-day.

\section{Accuracy}

The accuracy is the closeness of the results obtained by the method under study in relation to the true value for the quantitative analysis (ICH 2005). The accuracy was determined by testing the recovery of GFZ in ethanol, which was calculate the percentage of recovery of known amount of drug added to the sample using Equation 1.

\%Recovery: Y/X x100 \%

$\mathrm{Y}=$ absorbance of the sample; $\mathrm{X}=$ standard absorbance; acceptance criteria for recovery: 98-102\%.

\section{Limit of detection (LOD), limit of quantitation (LOQ)}

To determine the LOD and LOQ, three solutions prepared in triplicate, near the lower limit of the analytical curve. The LOD and LOQ were cal- culated based on the equations (2 and 3) as describe in $\mathrm{ICH}$ (2005), it is expressed as:

$$
\text { LOD }=3(\text { S.D./a) }
$$

$$
\mathrm{LOQ}=10(\text { S.D./a) }
$$

where S.D of $y$-intercepts and $S$ is the slope of the calibration curve.

\section{Robustness}

The robustness should show the reliability of an analysis related to deliberate variations in method parameters $\mathrm{ICH}$ (2005). The robustness was determined by analyzing the sample under the variation of the $\mathrm{pH}$ and manufacture of ethanol.

\section{Specificity}

The specificity was carried out under two standards: gemfibrozil and microemulsion without the drug, to determine that there would be no interference from the excipients present in the formulation.

\section{Encapsulation efficiency}

The entrapment efficiency (EE) was 
determined to access the extent of GFZ incorporation in the microemulsion. EE of GFZ-loaded MEs was determined by measuring the concentration of the free unloaded GFZ in the aqueous medium of the MEs suspension. Briefly, one gram of GFZ-loaded
MEs was weighted and ultracentrifuged for $20 \mathrm{~min}$ at $15000 \mathrm{rpm}$, approximately. Then, the amount of GFZ in the supernatant was determined by UV spectrophotometric analysis. The entrapment efficiency (EE) was calculated by the equation 4 .

$$
\mathrm{EE}(\%)=\frac{\text { Total mass of GFZ-mass of GFZ in aqueous phase }}{\text { Total mass of GFZ }} \times 100
$$

\section{RESULTS}

\section{Phase diagram construction}

In the present study a ternary phase diagram was construed and microemulsion region was found using surfactant concentration rate between $10-40 \%$. The Figure 1 exhibit the phase diagram and the photograph of the selected microemulsion.

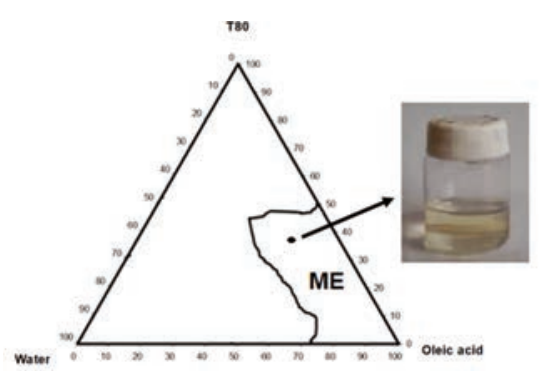

Figure 1. The photograph of selected microemulsion

\section{Polarized light microscopy}

The Figure 2 exhibit eh light microscopy to microemulsion containing GFZ

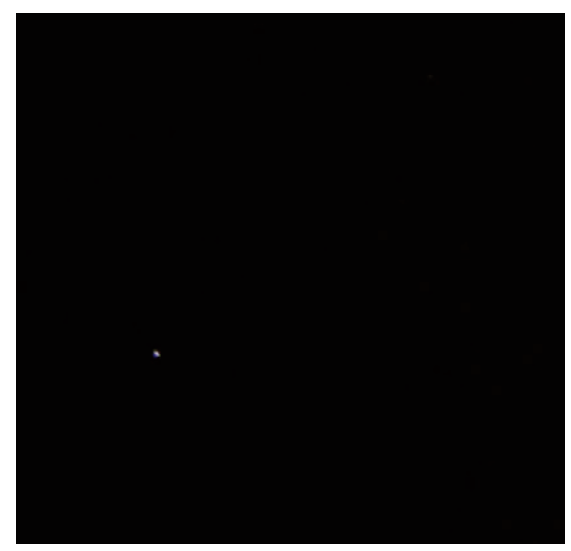

Figure 2. Light microscopy to microemulsion containing GFZ 


\section{Validation of analytical method}

\section{Lineality}

In order to obtain the linearity results, a calibrated analytical curve is cons- tructed, so that the dilutions are elaborated from a parent solution, the value obtained from $R^{2}$ is 0.9984 as shown in Figure 3 and the standard deviation values.

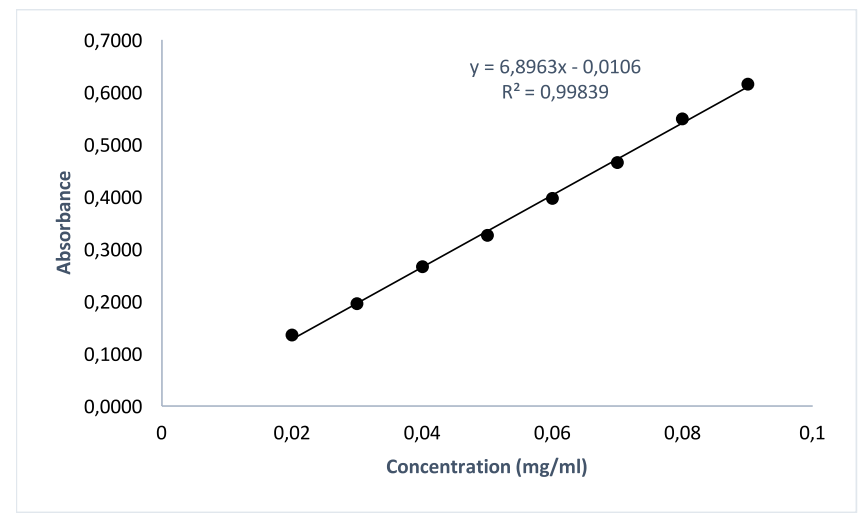

Figure 3. The linearity results

The standard deviation (SD) and coefficient of variation (CV) data is shown in Table 1.

\section{Precision}

This parameter was assessed by applying the intra and inter day tests through the analysis of 3 samples of different concentrations, the minimum $(0.02 \mathrm{mg} / \mathrm{mL})$, the medium $(0.05 \mathrm{mg} / \mathrm{mL})$ and the maximum $(0.09$ $\mathrm{mg} / \mathrm{mL}$ ) as showed in the Table 2 . 
Table 1. Standard deviation and coefficient of variation of the curve data

\begin{tabular}{|c|c|c|c|}
\hline $\begin{array}{l}\text { Concentration } \\
(\mathrm{mg} / \mathrm{mL})\end{array}$ & Average & DS ( $( \pm)$ & $\begin{array}{c}\text { CV } \\
\%\end{array}$ \\
\hline 0.09 & 0.6152 & 0.0102 & 1.66 \\
\hline 0.08 & 0.5492 & 0.0100 & 1.82 \\
\hline 0.07 & 0.4651 & 0.0027 & 0.58 \\
\hline 0.06 & 0.3964 & 0.0028 & 0.72 \\
\hline 0.05 & 0.3265 & 0.0042 & 1.29 \\
\hline 0.04 & 0.2662 & 0.0045 & 1.69 \\
\hline 0.03 & 0.1950 & 0.0035 & 1.79 \\
\hline 0.02 & 0.1358 & 0.0022 & 1.61 \\
\hline
\end{tabular}

Table 2. Standard deviation and coefficient of variation of the Inter and Intraday precision

\begin{tabular}{|c|c|c|c|c|c|c|c|}
\hline \multicolumn{4}{|c|}{ Interday } & \multicolumn{4}{|c|}{ Intraday } \\
\hline $\begin{array}{l}\text { Concentration } \\
(\mathrm{mg} / \mathrm{mL})\end{array}$ & Average & SD ( $( \pm)$ & $\begin{array}{l}\text { CV } \\
(\%)\end{array}$ & $\begin{array}{l}\text { Concentration } \\
(\mathrm{mg} / \mathrm{mL})\end{array}$ & Average & SD ( \pm$)$ & $\begin{array}{l}\text { CV } \\
(\%)\end{array}$ \\
\hline 0.09 & 0.5963 & 0.0029 & 0.48 & 0.09 & 0.6009 & 0.0006 & 0.10 \\
\hline 0.05 & 0.3262 & 0.0004 & 0.13 & 0.05 & 0,3263 & 0,0002 & 0,07 \\
\hline 0.02 & 0.1346 & 0.0004 & 0.27 & 0.02 & 0.1358 & 0.0005 & 0.37 \\
\hline
\end{tabular}

\section{Accuracy}

The accuracy of the proposed method was assessed by determining the average recoveries of samples using the standard addition method. The Table 3 show the results of accuracy.

Table 3. Accuracy test results

\begin{tabular}{ccccc}
\hline $\begin{array}{c}\text { Concentration } \\
(\mathrm{mg} / \mathrm{mL})\end{array}$ & Average & SD $( \pm)$ & CV \% & $\begin{array}{c}\text { Recovery } \\
(\%)\end{array}$ \\
\hline 0.09 & 0.5968 & 0.0018 & 0.30 & $101.15 \%$ \\
0.05 & 0.3389 & 0.0014 & 0.41 & $101.16 \%$ \\
0.02 & 0.1350 & 0.0005 & 0.39 & $99.11 \%$ \\
\hline
\end{tabular}




\section{Specificity}

The specificity of the method was evaluated under 2 standards gemfibrozil and microemulsion without drug, in order to determine that there was no interference from the excipients present in the formulation as shown in Figure 4.

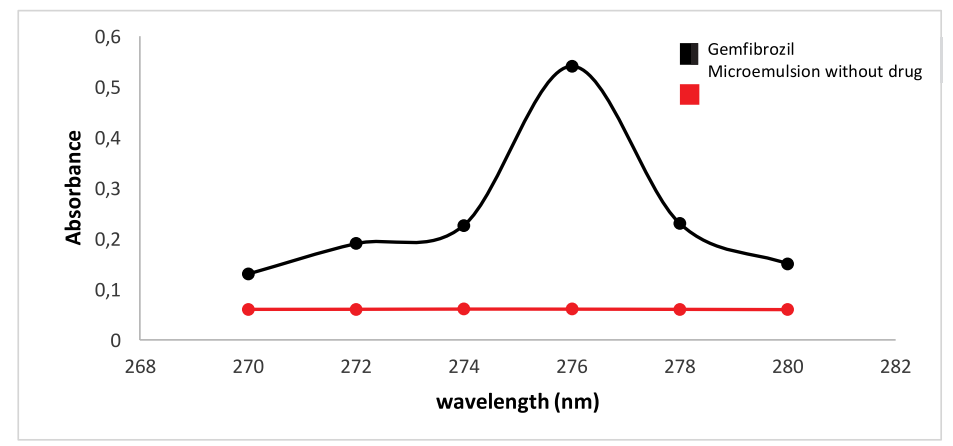

Figure 4. Specificity of microemulsion without gemfibrozil

\section{Robustness}

The robustness test was realized modifying the manufacture and the $\mathrm{pH}$ of the buffer solution. These parame- ters were selected due the ease access. The results of the selected variables in the robustness assessment are shown in Table 4. 
Table 4. Robustness test results

\begin{tabular}{|c|c|c|c|c|c|c|}
\hline \multirow{2}{*}{$\begin{array}{r}\text { Concentration } \\
0.05 \mathrm{mg} / \mathrm{mL}\end{array}$} & \multicolumn{3}{|c|}{ Buffer pH 7.0} & \multicolumn{3}{|c|}{ Buffer pH 7.4} \\
\hline & Average & SD ( \pm$)$ & CV \% & Average & SD $( \pm)$ & CV \% \\
\hline \multirow[t]{2}{*}{ Manufacture 1} & $\begin{array}{l}0.3267 \\
0.3264\end{array}$ & $\begin{array}{l}0.0001 \\
0.0002\end{array}$ & $\begin{array}{l}0.018 \\
0.047\end{array}$ & $\begin{array}{l}0.3263 \\
0.3264\end{array}$ & $\begin{array}{l}0.0003 \\
0.0002\end{array}$ & $\begin{array}{l}0.08 \\
0.047\end{array}$ \\
\hline & 0.3264 & 0.0002 & 0.071 & 0.3263 & 0.0002 & 0.064 \\
\hline \multirow[t]{3}{*}{ Manufacture 2} & 0.3262 & 0.0001 & 0.018 & 0.3265 & 0.0001 & 0.018 \\
\hline & 0.3260 & 0.0002 & 0.047 & 0.3263 & 0.0002 & 0.064 \\
\hline & 0.3259 & 0.0002 & 0.0469 & 0.3264 & 0.0001 & 0.0177 \\
\hline
\end{tabular}

\section{LOD and LOQ}

The detection limit is the lowest amount of the analyte that can be detected but do not necessarily quantified, while the limit of quantification is the lowest amount of the analyte that can be determined with accuracy and precision $\mathrm{ICH}$ (2005). The LOD and LOQ values were 0.062 and $0.189 \mathrm{mg} / \mathrm{mL}$ respectively, this results indicate the excellent sensitivity of the analytical method.

\section{Encapsulation efficiency}

The encapsulation efficiency to GFZ was $88 \%$ at the MEs. The results for both NLCs analyzed are close to those described by Addas et al. (2019) and were satisfactory, since they show high entrapment efficiency in the matrix of MEs.

\section{DISCUSSION}

In the present work, we have validated a method to quantification of gemfibrozil incorporated in the microemuslions. It is possible to observe a transparent solution with a single phase which indicates the formation of microemulsion. It is suggested due the spontaneous formation and thermodynamic stability, and a dark field was observed in the 
polarized microscopy which suggest the microemulsion formation. It was possible to observe the presence of a black field, which can suggest microemulsions formation. According to Froelich et al. (2017), a main feature of these microemulsion systems is dark field observation.

To validation method, it was demonstrates the linearity expressed by the relationship between the concentration of gemfibrozil present obtaining a value of $R^{2} 0.9984$, indicating that the curve is linear for the intended purpose. Similar results were found by Gaete (2014), the author validated an analytical methodology for the application of paracetamol in a bioexemption study, and obtained a value of 0.999 in the $R^{2}$, which indicated that the curve is linear for the purpose of the work.

The acceptance of linearity will depend on the value obtained in the correlation coefficient and the intersection of the line are its axis. This value indicates the linear regression of the concentration against absorbance. The correlation coefficient value equal to or greater than 0.99 is normally acceptable, since it indicates that the analytical curve is linear USP 39 NF 34 (2016). In this context, the analytical curve is considered as a reference for the quantification of gemfibrozil.

The data presented in Table 2 showed that the method is precise for the quantification of gemfibrozil incorporated at the microemulsion. The coefficient of variation values was below $0.5 \%$, which indicate that the method is sufficiently precise. The results are in accordance with the provisions of the ICH (2005), which suggests that the coefficient of variation for this parameter should be less than 3.0 \%. Cáceres, et al (2016) obtained a coefficient of variation of less than 1 $\%$, with the results presented, both authors argue that the method is accurate. With the above it is shown that the method is accurate for the intended purpose.

The results presented in the Table 3 are in accordance with the official validation regulations. The $\mathrm{ICH}$ (2005) stipulates that the recovery percentage must be in a range of 80 to $120 \%$. Lozano et al., (2018) validated an analytical method for the quantification of alprazolam in ta- 
blets, in the precise parameter, the results obtained a recovery of 100.69 $\%$, in this way, the authors indicated that the parameter is within the limits stipulated by ICH (2005) and USP 39 NF34 (2016).

The specificity of the drug could be determined by a wavelength scan, where we can show that the highest reading peak corresponds to the 276 $\mathrm{nm}$ suggested by USP 39 NF34 (2016) as the wavelength for GFZ. In addition, it can be evidenced that no interference is generated between ME without drug and the sample with GFZ demonstrating that microemulsion excipients do not interfere with gemfibrozil reading.

\section{CONCLUSION}

In the present project, a method proposed an analytical derivative UV spectrophotometric was developed. This method showed advantages related to the simplicity, fastness and low-cost conditions. All validation parameters were satisfactory, the re- sults showed that the method is suitable for quantification of gemfibrozil incorporated in microemulsion, as consistent with the requirements of $\mathrm{ICH}$, thus providing reliability to the analyses proposed.

\section{LIST OF REREFENCES}

Addas Rahdar; Taboada Pablo; Reza Hajinezhad Mohammad; Barani Mahmood; Beyzaei Hamid (2018). Effect of tocopherol on the properties of Pluronic F127 microemulsions: Physico-chemical characterization and in vivo toxicity. v 277, p. 624-630.

Benítez, N., Cordoví, J. M., Fernández, M., Zamora, R., De La Paz, N., \& Cabrera, P. (2014). Validación de métodos analíticos aplicables al control de calidad y estudio de estabilidad de las gotas nasales de efedrina. Ars Pharmaceutica, 55(3), 11-18. 
Cáceres, D. H., Zapata, J. D., Granada, S. D., Cano, L. E., \& Naranjo, T. W. (2016). Estandarización y validación en Colombia de una metodología basada en HPLC para la determinación de la concentración sérica de posaconazol. Revista Iberoamericana de Micologia, 33(4), 230-236.

Callender, S. P., Mathews, J. A., Kobernyk, K., \& Wettig, S. D. (2017). Microemulsion utility in pharmaceuticals: Implications for multi-drug delivery. International Journal of Pharmaceutics, 526(1-2), 425-442.

Cáñez-Carrasco, M. G., \& García-Alegría, A. M. (2015). Validación de un método analítico para la determinación de fósforo por espectrofotometría ultravioleta-visible. Biotecnia, 17(1), 32.

Cubas, J. M., Pimentel, R. G. C., Enrique, I., Merlín, M., \& Martínez, E. S. M. (2018). La espectroscopia UV-Vis en la evaluación de la viabilidad de células de cáncer de mama. Lat. Am. J. Phys. Educ. Vol, 12(2), 2307-1.

Davoodi, P., Lee, L. Y., Xu, Q., Sunil, V., Sun, Y., Soh, S., \&Wang, C.-H. (2018). Drug delivery systems for programmed and on-demand release. Advanced Drug Delivery Reviews.

El Maghraby, G. M., Arafa, M. F., \& Essa, E. A. (2018). Phase transition microemulsions as drug delivery systems. Applications of Nanocomposite Materials in Drug Delivery. Elsevier Inc.

Ferreira, G. F. D., Souza, D. R. Q., Lima, R., Lobato, A. K. C. L., Silva, A. C. M., \& Santos, L. C. L. (2018). Novel glycerin-based microemulsion formulation for enhanced oil recovery. Journal of Petroleum Science and Engineering, 674-681.

Froelich, A., Osmałek, T., Snela, A., Kunstman, P., Jadach, B., Olejniczak, M., Roszak, G., Białas, W. (2017) Novel microemulsion-based gels for topical delivery of indomethacin: Formulation, physicochemical properties and in vitro drug release studies, Journal of Colloid and Interface Science

Gaete, F. (2014). Validación de la metodología analítica de Paracetamol y aplicación a un estudio de bioexención. Santiago. 
Gvaramia, M., Mangiapia, G., Falus, P., Ohl, M., Holderer, O., \& Frielinghaus, H. (2018). Capillary condensation and gelling of microemulsions with clay additives. Journal of Colloid and Interface Science, 525, 161-165.

Huo, R., Yang, X. L., Liu, Y. Q., \& Xu, Y. H. (2017). Visible-light photocatalytic degradation of glyphosate over BiVO4 prepared by different co-precipitation methods. Materials Research Bulletin, 88, 56-61.

ICH Validation of analytical procedures: text and methodology Q2(R1) (2005). International Conference on Harmonization, 1-13.

Lozano, X., Zhang, S., Ma, H., Dong, P., Ma, X., Xu, M., Zhang, J. (2018). In situ monitoring of the structural change of microemulsions in simulated gastrointestinal conditions by SAXS and FRET. Acta Pharmaceutica Sinica B, 8(4), 655-665.

Silva, C. F.; Severino, P.; Martins, F.; Chaud, M.V.; Santana, M.H.A. (2008). The intestinal permeation of didanosine from granules containing microspheres using the everted gut sac model. 1-6

Tornio, A., Neuvonen, P. J., Niemi, M., \& Backman, J. T. (2017). Role of gemfibrozil as an inhibitor of CYP2C8 and membrane transporters. Expert Opinion on Drug Metabolism and Toxicology, 13(1), 83-95.

United States Pharmacopea USP39 NF34 (2016)

Valcárcel, J. P., González, H., \& Valcárcel, D. H. (2008). Espectroscopia. fundamento de la resonancia magnética nuclear. Entornos, 1(21), 89-94. 